\title{
EFFECT OF PARTICLE SIZE ON FLOW BEHAVIOR IN FLUIDIZED BEDS
}

\author{
RAMESH TIMSINA, RAJAN K. THAPA, BRITT M. E. MOLDESTAD \& MARIANNE S. EIKELAND \\ Department of Process, Energy and Environmental Technology, University of South-Eastern Norway, \\ Kjølnes Ring 56, 3901, Porsgrunn, Norway.
}

\begin{abstract}
The fluidization behaviour depends on particle properties such as particle size, sphericity, density and the properties of the fluidizing agent. In this study, the effects of different particle sizes on fluidization behaviour were investigated. Experiments were done by mixing sand particles of mean diameter 293 $\mu \mathrm{m}$ (small particle) and $750 \mu \mathrm{m}$ (large particle). The experiment with $20 \%$ small particles and $80 \%$ large particles gave a reduction in minimum fluidization velocity of $60.8 \%$ compared to the minimum fluidization velocity with only large particles. CPFD simulations were performed using the commercial software Barracuda ${ }^{\circledR}$. There is a good agreement between the results from the experiments and the simulations. The minimum fluidization velocity is also calculated using different theoretical equations based on the average particle size for the mixture. The obtained experimental results were compared with the minimum fluidization velocity calculated using different equations available in the literature. There are significant differences in minimum fluidization velocities obtained from the different empirical equations. The pressure drop profiles for large and small particles follow the trends presented in the literature. The experimental minimum fluidization velocities were found to be 0.46 and $0.092 \mathrm{~m} / \mathrm{s}$ for the large and small particles respectively.

Keywords: bubbling fluidized bed, fluidization, particle size.
\end{abstract}

\section{INTRODUCTION}

The fluidization technology is used in several industrial operations due to uniform heat and mass transfer. Industrial applications such as calcination and roasting of minerals, combustion, gasification, flue-gas desulphurization, chemical reactors use the fluidization technology. The technology involves complex multiphase flows, heat and mass transfer and several reactions within the bed.

Gasification of biomass is a thermochemical conversion process, which gives product gases such as $\mathrm{CO}, \mathrm{H}_{2}, \mathrm{CO}_{2}$ and $\mathrm{CH}_{4}$, together with tar and a solid residue consisting of ash and char [1]. Fluidized beds are commonly used for biomass gasification. The fluidized bed technology uses bed material to heat up the biomass particles to a temperature range of $700-900^{\circ} \mathrm{C}[2]$. Even distribution of heat and mass transfer and excellent solid mixing make the fluidized bed gasification one of the attractive technologies for biomass gasification.

In a bubbling fluidized bed gasifier, the fluidizing agent such as air or steam is introduced from the bottom of the bed. The fluidizing agent keeps the bed in a fluid like state. The fluidized bed biomass reactors operate within the bubbling fluidization regime. The fluidization regime is very much dependent on particle size, particle size distribution, solid density (compactness of the substance) and the sphericity of particles (sphericity gives a rough estimation of a particle shape) and the properties of the fluidizing agent. It is important to investigate the effects of these parameters on the performance of a fluidized bed biomass gasification reactor.

Velocity measures the quantity of the fluidizing agents into the bed materials. When a fluid at low velocity is introduced into a bed of solid particles, fluid hardly percolates in between the space present between the solid particles. With an increase in the fluid velocity, a point is 
achieved where all the solid particles are suspended by upward flowing fluid. The bed at this state is called the bed at minimum fluidization. The velocity with which the bed fluidizes is known as the minimum fluidization velocity. Any other velocity with which the bed fluidizes is called the fluidization velocity. The difference between the fluidization velocity and the minimum fluidization velocity is known as excess velocity.

Industrial fluidized beds use bed materials with size distributions. Bed hydrodynamics change significantly with small changes in particles size and particle size distributions. The average size of the mixture changes with change in particles size distribution of the mixture. A mixture of the same particle species with different average sizes gives the minimum fluidization velocity in between the minimum fluidization velocities of the two particles [3]. The mixing state of the binary systems in fluidized beds are classified as (a) complete mixing (b) complete segregation (c) partial mixing [4].

Jayarathna and Halvorsen [5] have studied the minimum fluidization velocity and bed expansion for mixtures of particles with different sizes. Spherical glass powders were used in their experiments, and it was found that the minimum fluidization velocity decreased with increase in the concentration of the small particles in the mixture.

Mixtures of different particle sizes show the phenomenon of particle segregation. Segregation reduces the heat and mass transfer and the expansion of the bed. Huilin et al. [6] investigated the mixing and segregation of particles in a fluidized bed. Simulations were performed to study the flow behaviour and segregation of particles in a mixture based on Eulerian-Eulerian approach and kinetic theory of granular flow for a binary mixture. Smaller particles tend to accumulate towards the top of the bed and larger particles tend to move towards the bottom of the bed [6].

The minimum fluidization velocity for the binary particles with large difference in sizes and densities were studied by Noda et al. [4]. Experiments were performed to develop an equation for predicting the minimum fluidization velocity for the binary systems such as wood chips, iron beads, soya bean with sands/glass beads.

Oliveira et al. [7] developed an experimental correlation for the minimum fluidization velocity for the binary mixture of sand and biomass. The bed hydrodynamics is directly related to the biomass shape and size. The different combinations of biomass and sand exhibits the state of complete mixing, complete segregation and partial mixing [7].

Perez et al. [8] studied minimum fluidization velocity for the mixture of sugarcane bagasse particles and the quartz sand. The minimum fluidization velocity increased with increase in the amounts of large particles (biomass) as well as increase in the size of the large particles. The developed correlation based on the experiments gives approximately accurate minimum fluidization velocities [8].

Ramakers et al. [9] have studied the minimum fluidization and the bed porosity for the mixture of wood particles and sand. The results showed the different results compared to the values obtained from the correlations from literature. The experimental results have a clear trend. For complete mixing of sand and the wood particles, a maximum of 10 weight $\%$ of wood particles should be used with superficial gas velocity of around 3-4 times the minimum fluidization velocity [9].

Paudel and Feng [10] developed a correlation based on the weight percentage for a mixture of biomass (corn cobs and walnut shells) and bed material (sand, glass beads and alumina). The results from the correlations were in good agreement with the experimental results [10].

The particles size and the proportion of the different species in the bed influences the complete mixing in the bed. Hence, the experiments and the simulations were performed to 
determine the minimum fluidization velocity for mixtures of small and large particles. The experiments were done by mixing sand particles with particle sizes of 150-400 $\mu \mathrm{m}$ (mean diameter $293 \mu \mathrm{m}$ ) and 600-850 $\mu \mathrm{m}$ (mean diameter $750 \mu \mathrm{m}$ ). Air was used as the fluidizing agent. The experimental minimum fluidization velocities were compared with the theoretical minimum fluidization velocities.

\section{THEORETICAL BACKGROUND}

Fluid flow rate gives the quantity of the fluidizing agents per unit time. When the fluid flow rate into the bed of solid particles with a range of particle sizes is increased, the smaller particles move towards the voids present in between the large particles. The large particle in the mixture tends to remain in stationary conditions up to certain airflow rate, at which the bed starts to fluidize. Further increase of air velocity into the bed gives segregation and settling of particles. The large particles tend to settle down towards the bottom of the bed and the smaller particles move towards the top of the bed [11]. Segregation is a non-desired phenomenon in a fluidized bed. Therefore, the study of particle size distribution in the fluidized bed is of great significance. Considering the fluidization behaviour of the particles, Geldart defined them into four different groups. Geldart's classification of particles is presented in Fig. 1. The abscissa represents the average size of the mixture $(\mu \mathrm{m})$ in logarithmic scale and the ordinate represents the difference in density of the bed material and the gas density $\left(\mathrm{g} / \mathrm{cm}^{3}\right)$.

Group C particles are a small fine cohesive particle with very high interparticle forces. Fluidization of group $\mathrm{C}$ particles gives rise to channelling or plugging of the bed. Group A particles are ideal for fluidization because of good solid mixing of particles at relatively low fluid velocity. The bubbles split and coalesce several times while passing through the bed during fluidization. Group B particles have good solid mixing and heat transfer between the biomass and bed materials. The bubbles grow and coalesce as they move upwards. Group D particles have a large diameter. It is difficult to fluidize group D particles as the bubbles coalesce rapidly along the bed and exhibit severe channelling, spouting and exploding behaviour [11]. Most of the fluidized bed gasifiers use Geldart B particles as a bed material, and therefore this study was focused on group B particles.

The different types of particles have different minimum fluidization velocity. Moreover, the fluidization characteristics of a bed depend on density, excess velocity and the particle

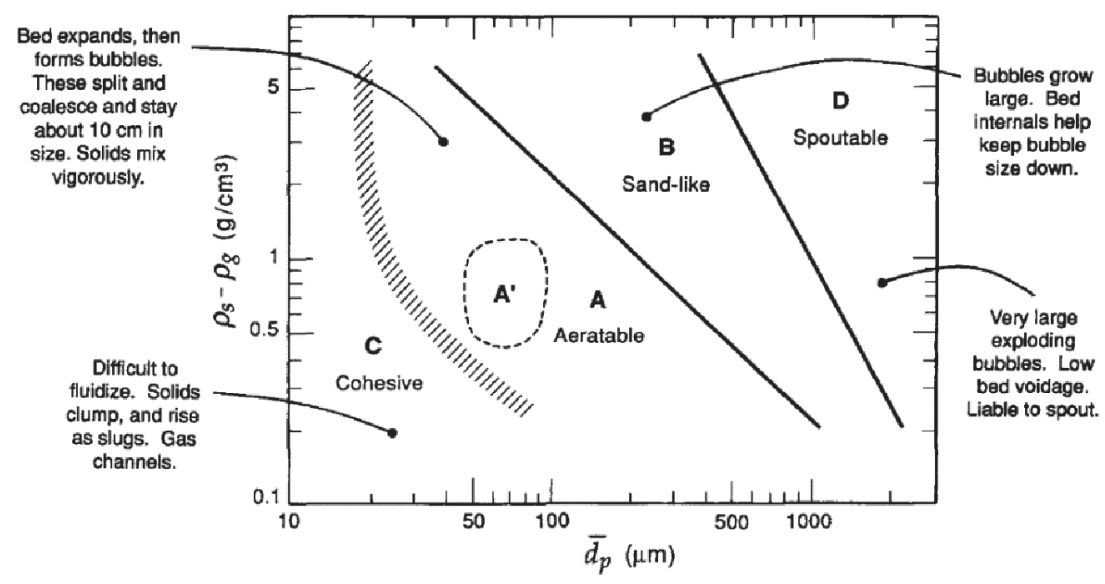

Figure 1: Particle behaviour when suspended by gas [12]. 
size distribution. Bulk density takes the account of voids present in the solid mixture, given by the ratio of weight of solids divided by the total volume occupied by solids and the voids. Bulk density changes with the change in particle size distribution. Ergun proposed the mathematical model to predict the fluid flow through a bed of solid particles. The model gives the minimum fluidization velocity of the bed material used in fluidized bed gasification reactor.

The pressure drop, $\Delta \mathrm{P}$, across the bed of height $\mathrm{L}$, containing solids with a particles diameter $d_{p}$ is given by Ergun equation [11].

$$
\frac{\Delta \mathrm{P}}{\mathrm{L}}=\frac{150 \mu}{\Phi_{\mathrm{p}}{ }^{2} \mathrm{~d}_{\mathrm{p}}{ }^{2}} \frac{(1-\varepsilon)^{2}}{\varepsilon^{3}} \mathrm{U}+\frac{1.75 \rho_{\mathrm{g}}}{\Phi_{\mathrm{p}} \mathrm{d}_{\mathrm{p}}} \frac{(1-\varepsilon)}{\varepsilon^{3}} \mathrm{U}^{2}
$$

where $\Delta \mathrm{P}$ is the pressure drop due to the weight of the bed, $\mathrm{U}$ is the superficial gas velocity, $\mu$ is the dynamic fluid viscosity, $\Phi_{\mathrm{p}}$ is the sphericity, $\varepsilon$ is the voidage (space left in between the solid particles) of the bed and $\rho_{\mathrm{g}}$ is the gas density.

At minimum fluidization condition, all the solid particles are suspended in the bed. The drag force between the upward flowing gas and the bed materials is balanced by the weight of the particles at minimum fluidization.

$$
\underbrace{\left(\begin{array}{c}
\text { Pressure } \\
\text { drop } \\
\text { across bed }
\end{array}\right)\left(\begin{array}{c}
\text { crosssectional } \\
\text { area } \\
\text { of bed }
\end{array}\right)}_{\text {Drag force }}=\underbrace{\left(\begin{array}{c}
\text { volume } \\
\text { of } \\
\text { bed }
\end{array}\right)\left(\begin{array}{c}
\text { fraction } \\
\text { consisting } \\
\text { of solids }
\end{array}\right)\left(\begin{array}{c}
\text { specific } \\
\text { weight } \\
\text { of solids }
\end{array}\right)}_{\text {Particle weights }}
$$

For positive $\Delta \mathrm{P}[11,13]$,

$$
\Delta \mathrm{P} A_{t}=A_{t} L_{m f}\left(1-\varepsilon_{\mathrm{mf}}\right)\left[\left(\rho_{\mathrm{s}}-\rho_{\mathrm{g}}\right) \frac{\mathrm{g}}{g_{c}}\right]
$$

Here, $A_{t}$ is the cross-sectional area of the bed, $L_{m f}$ is the height of the bed at minimum fluidization conditions, $\varepsilon_{\mathrm{mf}}$ is the voidage at minimum fluidization, $\rho_{\mathrm{s}}$ is the density of bed materials, $\mathrm{g}$ is the acceleration due to gravity and $g_{c}$ is the force-weight conversion factor. The forceweight factor can be ignored for flow with gases unless the bed is deep at high pressure [11].

Or

$$
\frac{\Delta \mathrm{P}}{L_{m f}}=\left(1-\varepsilon_{\mathrm{mf}}\right)\left(\rho_{\mathrm{s}}-\rho_{\mathrm{g}}\right) \mathrm{g}
$$

The superficial gas velocity $\mathrm{U}_{\mathrm{mf}}$ at minimum fluidization conditions can be calculated by combing the eqn (1) and eqn (4). The solution for $\mathrm{U}_{\mathrm{mf}}>0$ [14] gives:

$$
\mathrm{U}_{\mathrm{mf}}=\frac{\left\{-150 \mu\left(1-\varepsilon_{\mathrm{mf}}\right)+\sqrt{\left[150 \mu\left(1-\varepsilon_{\mathrm{mf}}\right)\right]^{2}+7 \rho_{\mathrm{g}} \varepsilon_{\mathrm{mf}}{ }^{3} \Phi_{\mathrm{p}}{ }^{3} \mathrm{~d}_{\mathrm{p}}{ }^{3}\left(\rho_{\mathrm{s}}-\rho_{\mathrm{g}}\right) \mathrm{g}}\right\}}{3.5 \rho_{\mathrm{g}} \Phi_{\mathrm{p}} \mathrm{d}_{\mathrm{p}}}
$$

Further, eqns (1) and (4) can be simplified in the form of Reynolds and Archimedes number at minimum fluidization condition as follows [11]. 


$$
\underbrace{\frac{1.75}{\Phi_{\mathrm{p}} \varepsilon_{\mathrm{mf}}{ }^{3}} \operatorname{Re}_{\mathrm{p}, \mathrm{mf}}{ }^{2}}_{\text {Inertial part }}+\frac{150\left(1-\varepsilon_{\mathrm{mf}}\right)}{\Phi_{\mathrm{p}}{ }^{2} \varepsilon_{\mathrm{mf}}{ }^{3}} \operatorname{Re}_{\mathrm{p}, \mathrm{mf}}-\mathrm{Ar}=0
$$

where $\operatorname{Re}_{p, m f}=d_{p} U_{m f} \rho g / \mu$ and $\operatorname{Ar}=\rho_{g} d_{p}{ }^{3} g\left(\rho_{s}-\rho_{g}\right) / \mu^{2}$. The first term represents the inertial part and the second term represents the viscous part in eqn (6). Further, eqn (6) can be written as:

$$
\mathrm{K}_{1} \operatorname{Re}_{\mathrm{p}, \mathrm{mf}}^{2}+\mathrm{K}_{2} \operatorname{Re}_{\mathrm{p}, \mathrm{mf}}-\mathrm{Ar}=0
$$

Where

$$
\mathrm{K}_{1}=\frac{1.75}{\Phi_{\mathrm{p}} \varepsilon_{\mathrm{mf}}{ }^{3}} \text { and } \mathrm{K}_{2}=\frac{150\left(1-\varepsilon_{\mathrm{mf}}\right)}{\Phi_{\mathrm{p}}{ }^{2} \varepsilon_{\mathrm{mf}}{ }^{3}}
$$

The voidage and the sphericity are the critical factors to determine the minimum fluidization velocity. The voidage at minimum fluidization is strongly dependent on the particle sphericity. The Ergun equation calculates the pressure-drop based on the voidage and the sphericity of the fixed bed. This does not give the exact pressure drop at transient fluidization conditions. There are different empirical correlations developed by different researchers to predict the minimum fluidization velocity for different operating conditions. Some of the correlations are presented in Table 1.

In general, the inertial part in Ergun's equation is neglected for small particles with $\mathrm{Re}_{\mathrm{p}, \mathrm{mf}}$ $<20$ [11]. This simplifies the eqn (5) to:

$$
\mathrm{U}_{\mathrm{mf}}=\frac{\mathrm{d}_{\mathrm{p}}{ }^{2}\left(\rho_{\mathrm{s}}-\rho_{\mathrm{g}}\right) \mathrm{g}}{150 \mu} \frac{\Phi_{\mathrm{p}}{ }^{2} \varepsilon_{\mathrm{mf}}{ }^{3}}{1-\varepsilon_{\mathrm{mf}}}
$$

\section{EXPERIMENTAL}

The experiments were done in a laboratory scale bubbling fluidized bed available at the University of South-Eastern Norway. The experimental set-up along with a

Table 1: Empirical equations for minimum fluidization velocity by different authors.

\begin{tabular}{ll}
\hline Author & Equation \\
\hline Wen and Yu [15] & $\mathrm{U}_{m f}=\frac{\mu_{g}}{\rho_{g} d_{p}}\left(\sqrt{33.7^{2}+0.0408 A r}-33.7\right)$ \\
Richardson et al. $[11,16]$ & $\mathrm{U}_{m f}=\frac{\mu_{g}}{\rho_{g} d_{p}}\left(\sqrt{25.7^{2}+0.0365 A r}-25.7\right)$ \\
Doichev and Akhmakov [17] & $\mathrm{U}_{m f}=\frac{\mu_{g}}{\rho_{g} d_{p}}\left(1.08 \times 10^{-3} A r^{0.947}\right)$ \\
Barbosa et al. $[18]$ & $\operatorname{Re}_{m f}=1.9 \times 10^{-3} A r^{0.87} \mathrm{U}_{m f}=\frac{\operatorname{Re}_{m f} \mu}{\rho_{g} d_{p}}$ \\
\hline
\end{tabular}


simplified sketch are presented in Figure 2. The experimental setup consists of pressure measurement sensors connected to a computer program, airflow supply and the fluidized bed. The pressure sensors measure the pressure within the bed for different airflow rates. LabVIEW is used to acquire the data measured by the pressure sensors at the wall of the column. Compressed air at ambient temperature is supplied from the bottom of the bed. The supplied air passes through a porous plate distributor for even distribution of airflow into the bed. The airflow rate is controlled by the pressure reduction valve and is measured by a digital flow meter. The bed consists of a transparent plastic cylinder with height (h) $1.5 \mathrm{~m}$ and diameter (D) $84 \mathrm{~mm}$. The second pressure sensor (P2) lies $35 \mathrm{~mm}$ above the air distributor and the distance between the sensors is $100 \mathrm{~mm}$.

The experiments were carried out with the different proportions of large and small particles. Sand particles with different mean diameters were used for the experiments. The small particles were in the range of $150-400 \mu \mathrm{m}$ and the large particles were in the range of $600-850 \mu \mathrm{m}$. The various parameters used for the experiments are presented in Table 2.

The bed volume for each of the experiments was $1200 \mathrm{ml}$. The composition of the small particles in the experimental sample were $0 \%$ (pure large particles), 10\%, 20\%, 30\%, 40\%, $50 \%, 60 \%, 75 \%$, and $100 \%$. The solid volume fraction was calculated based on the weight of a known volume of sand. The particles were mixed thoroughly before pouring into the bed column. The air flow rate was gradually increased until the bed reached the fluidization state. The minimum fluidization velocity was calculated using the empirical correlations shown in Table 1. The voidage at minimum fluidization conditions was taken as the solid void fraction at fixed bed condition for all the theoretical calculations. All of the obtained experimental values for the minimum fluidization velocity satisfied the conditions of $\operatorname{Re}_{\mathrm{p}, \mathrm{mf}}$ $<20$. The theoretical minimum fluidization velocities based on only the viscous term of eqn (4) is also calculated.

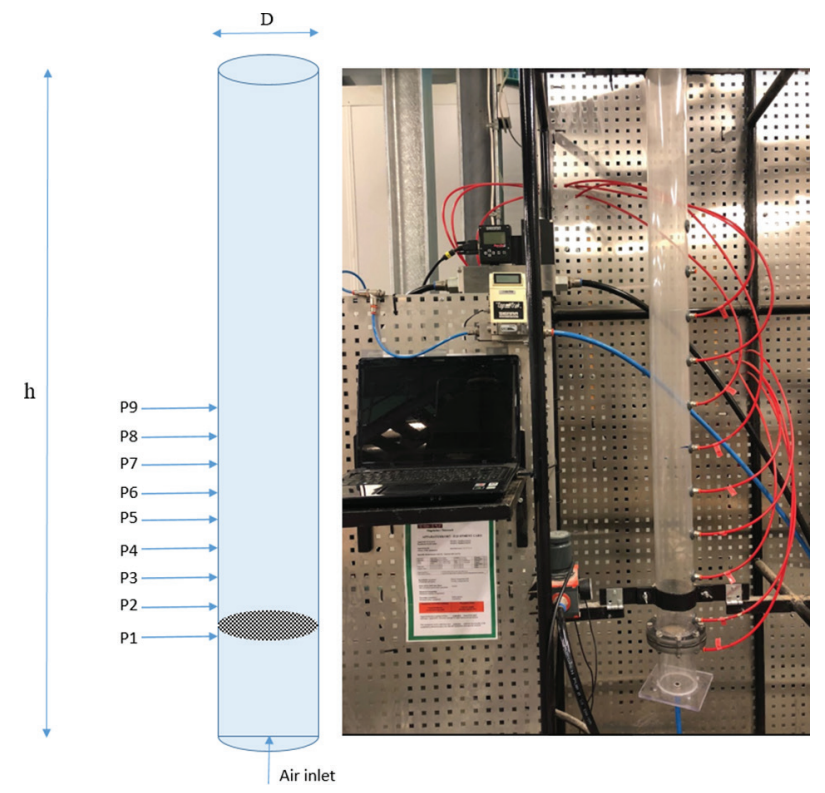

Figure 2: Experimental setup for bubbling fluidized bed. 
Table 2: Various experimental parameters.

\begin{tabular}{ll}
\hline Particle density & $2650 \mathrm{~kg} / \mathrm{m}^{3}$ \\
Air density & $1.225 \mathrm{~kg} / \mathrm{m}^{3}$ \\
Air viscosity & $1.8 \times 10-5 \mathrm{~Pa} . \mathrm{S}$ \\
Solid void fraction & $0.49-0.50$ \\
Superficial gas velocity & $0.03-0.6 \mathrm{~m} / \mathrm{s}$ \\
\hline
\end{tabular}

\section{COMPUTATIONAL MODEL}

Computational fluid dynamics (CFD) are used to model the systems handling the fluid flow. Conventional CFD is a well-accepted technique for single-phase systems. Multiphase CFD models use either an Eulerian-Eulerian, or Eulerian-Lagrangian approach. The EulerianEulerian approach models the solid and gas phase separately with Navier-Stokes equation. The discrete particle phase is not considered in Eulerian modelling and are solved with the kinetic theory of granular flow. In the Eulerian-Lagrangian approach, fluid is treated as a continuous phase and the particles as a discrete phase. The solid particles are approximated with Newton's law of motion. This gives high loading to CPU during simulations and is often limited to 2D or quasi-3D and in the order of $10^{4}$ number of particles [19]. The MP PIC modelling is based on the Eulerian approach for fluid particles and Lagrangian approach for the solid particles. Barracuda ${ }^{\circledR}$ is a software package based on the MP PIC modelling, which is known as the Computational Particle Fluid Dynamics (CPFD) approach.

A simulation model was developed to compare the minimum fluidization velocity obtained from the experiment. The operating parameters for the simulation models are same as that of the experimental study. The results from the simulation modelling are validated against the experimental results to give an acceptable result for the minimum fluidization velocity for the mixture.

\section{RESULTS AND DISCUSSIONS}

The pressure drop profiles with respect to superficial gas velocity for large and small particles are presented in Figure 3. The presented figure shows the pressure drop profile and the minimum fluidization velocity for the large and the small particles.

The minimum fluidization velocity is $0.46 \mathrm{~m} / \mathrm{s}$ for the large particles. The pressure drop at the minimum fluidization condition is $116 \mathrm{mbar} / \mathrm{m}$ for the large particles. The minimum fluidization velocity is $0.092 \mathrm{~m} / \mathrm{s}$ for the small particles. The pressure drop at the minimum fluidization condition is $122 \mathrm{mbar} / \mathrm{m}$ for the small particles. The pressure drop profile for both particles follows the similar trends presented in the literature by Kunni et al. [11].

The obtained results from the experiments were validated using a simulation model based on CPFD approach in Barracuda. Figure 4 shows the comparison of the pressure drop along the bed for a particle with mean diameter $293 \mu \mathrm{m}$.

There is some deviation of the pressure drop for the static bed (before the minimum fluidization velocity). The minimum fluidization velocity from the simulation model is $0.09 \mathrm{~m} / \mathrm{s}$ and $0.092 \mathrm{~m} / \mathrm{s}$ from the experiment. The results from the simulations have a good agreement with the results from the experiments. Further the experiments and the simulations were done for each of the mixtures of large and small particles as described above and the minimum fluidization velocity of the mixture were calculated.

The minimum fluidization velocity of the mixtures with different composition of small and large particles was investigated in this study. Figure 5 gives the minimum fluidization velocity for the mixture of different proportion of small and large particle. 


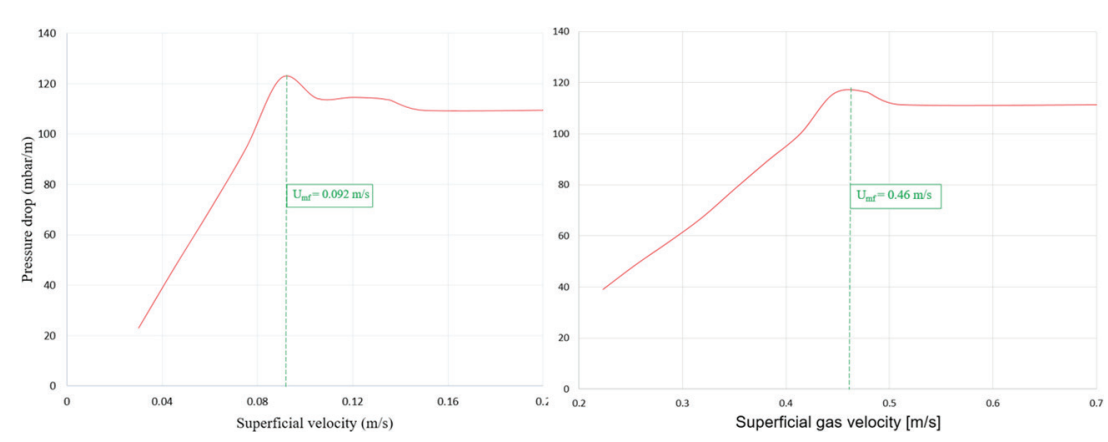

Figure 3: Pressure gradient profile for a): small particles $\left(d_{p}=293 \mu \mathrm{m}\right)$ b): large particles $\left(d_{p}=750 \mu \mathrm{m}\right)$.

The minimum fluidization velocity decreases with the addition of small particles in the mixture. The experiment with $20 \%$ small particles and $80 \%$ large particles gives a reduction in minimum fluidization velocity of $60.8 \%$ compared to the minimum fluidization velocity with only large particles. The addition of small particles can bring down the operating air velocity of fluidized bed biomass gasifiers. Biomass gasification reactors are usually operated in the bubbling regime. Higher air velocity provides high amounts of oxygen to the reactor, which can be undesirable. This is because the gasification is a thermochemical process that should be operated with limited supply of oxygen and excess supply of oxygen can convert the gasification process into combustion.

The simulation results agree well with the experimental results. Different drag models available in Barracuda are used in the simulations. It was found that the Wen-Yu-Ergun model gives the best prediction for the mixtures with up to $40 \%$ small particles. The Wen-Yu model agree with the experimental results with $50 \%$ small and $50 \%$ large particles. The mixtures with $60 \%$ and $75 \%$ small particles are well predicted by using the Ergun drag model. The different drag models also affect the value of the minimum fluidization velocity.

The theoretical minimum fluidization velocities calculated using equations presented in Table 1 deviates significantly from the measured minimum fluidization velocity. The theoretical minimum fluidization velocities were calculated based on the mean particle size for the

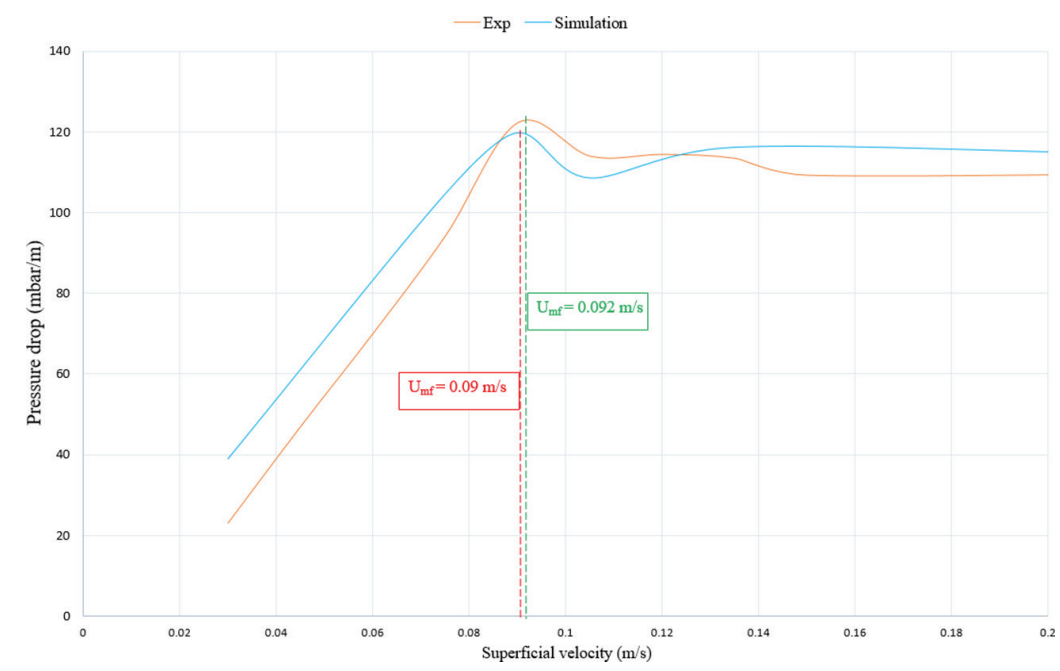

Figure 4: Pressure drop for small particles $\left(d_{p}=293 \mu \mathrm{m}\right)$ (experiment and simulation). 


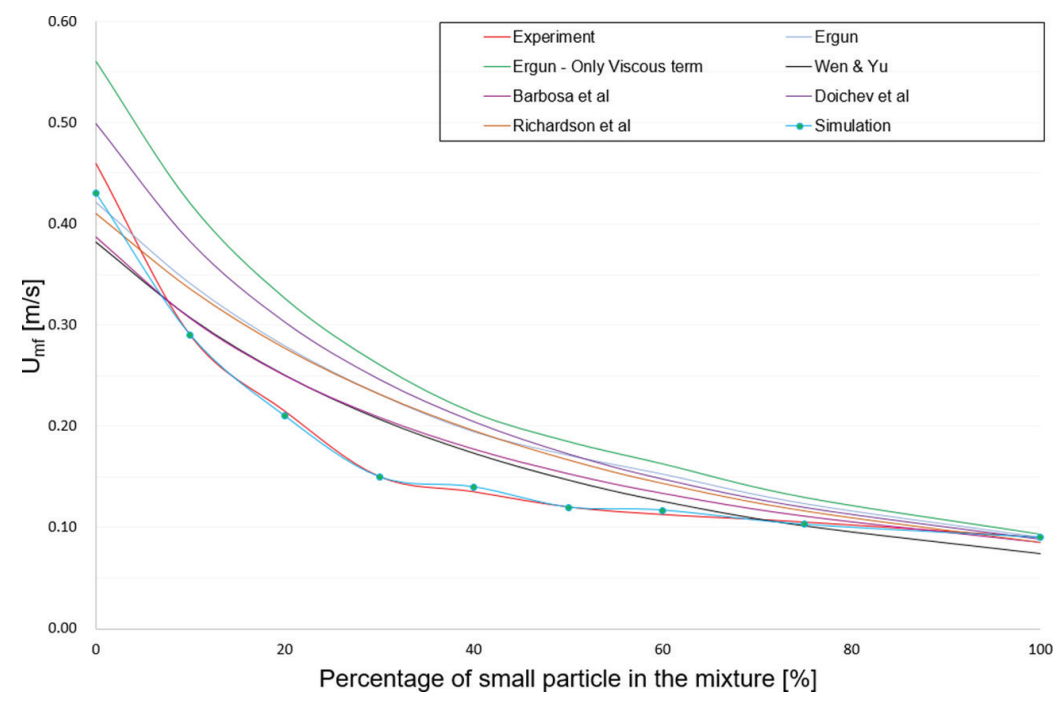

Figure 5: Minimum fluidization velocity.

mixture. For example, the minimum fluidization velocity based on Ergun equation deviates from the experimental result by $0 \%-35 \%$. There is a deviation of $0 \%-28 \%$ with the Wen and Yu relationship compared to the experimental results. The Doichev et al. equation gives a deviation of $0 \%-41 \%$. There are significant differences in minimum fluidization velocity based on different correlations for the mixtures with less than $40 \%$ of the small particle. This is mainly due to that the calculation of minimum fluidization velocity is based on the average particle diameter of the mixture. The calculated minimum fluidization velocity considering only the viscous term of the mixture gives a deviation of $3 \%-45 \%$. The deviation increases with the increase of the proportion of the large particles in the mixture.

In the experiments sand with a wide range of particle sizes are used. The particle size distributions are not considered when calculating the theoretical minimum fluidization velocity from the different correlations, whereas the simulation model accounts of the particles size distributions of the mixture. The screenshot of the simulations of different compositions of small particles in the mixture is presented in the Figure 6.

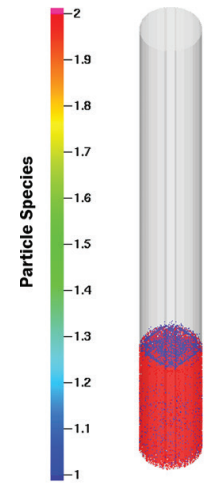

(a)

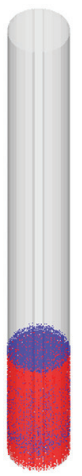

(b)

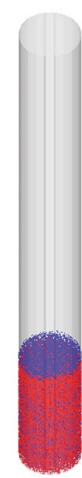

(c)

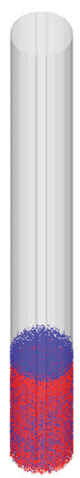

(d)

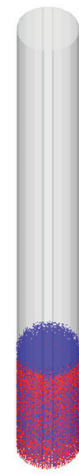

(e)

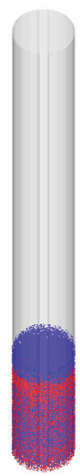

(f)

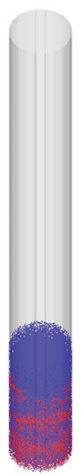

(g)

Figure 6. Particles distribution of the mixtures at bubbling regime (1- small particles, 2- large particles) 
Figure 6 (a)-(f) show the particles distributions for the mixture with 10\%-60\% small particles and Figure $6(\mathrm{~g})$ shows the particle distributions of the mixture with $75 \%$ small particles and $25 \%$ large particles. The particle mixtures are well distributed with a degree of accumulation of small particles at the top of the bed for all the cases. Overall, it can be argued that there is a good mixing for the mixture with $10 \%-30 \%$ of small particles. The addition of $10-30 \%$ of small particles into the large particles can bring down the operating fluid velocity for the bubbling bed reactor. This makes the operation simple and decreases the required flow rate of air or steam into the system. The stability of the gasification process is a major challenge particularly involving the use of steam as a fluidizing agent. Steam at high temperature and pressure is challenging to handle and may cause loss of property and lives. Thus, the reduction of the required amounts of steam flow rate to the gasification process can reduce the issues related to the high requirement of fluidizing agent.

\section{CONCLUSION}

The experiments and the simulations were performed with two different sized sand particles. The minimum fluidization velocity for large and small particles as well as for the mixture of small and large particles were calculated. The theoretical minimum fluidization velocities for different particle mixtures are also calculated using different correlations for the drag function. The experimental minimum fluidization velocity is $0.46 \mathrm{~m} / \mathrm{s}$ and $0.092 \mathrm{~m} / \mathrm{s}$ for the large and small particles respectively. The theoretical minimum fluidization velocity calculated based on the different equation lies close to the experimental value for the small particles. There is a significant difference in minimum fluidization velocity for the mixture with different proportion of small and large particles based on the empirical relationships. The Doichev et al. equation gives a deviation of $0-41 \%$ in the calculation of the minimum fluidization velocity compared to the experimental results. The deviation increases with the decrease of small particles in the mixture.

The experiment with $20 \%$ small particles and $80 \%$ large particles gives a reduction in minimum fluidization velocity of $60.8 \%$ compared to the minimum fluidization velocity with $100 \%$ large particles. Using this mixture can reduce the operating velocity of a fluidized bed biomass gasifier significantly. The experiments and simulations with mixtures of small and large particles showed some degree of particle segregation. Larger particles tend to settle down towards the bottom of the bed and the smaller particles tend to accumulate towards the upper half of the bed. There is good mixing for the mixture with 10\%-30\% of small particles at a fluid velocity close to the minimum fluidization velocity. Future work includes a development of a drag model that satisfies the experimental results for all the compositions of the small and the large particles in the mixture. The deviations of the theoretical correlations are due to the fact that the correlations do not account for the particle size distribution of the mixture.

\section{ACKNOWLEDGEMENTS}

The author would like to thank the University of South-Eastern Norway for providing all the necessary arrangements for the experimental work.

\section{REFERENCES}

[1] Bandara, J.C., Moldestad, B.M. \& Eikeland, M.S., Analysing the effect of temperature for steam fluidized-bed gasification of biomass with MP-PIC simulation. Journal homepage: www. IJEE. IEEFoundation. org, 9(6), pp. 529-542, 2018.

[2] Franco, C., Pinto, F., Gulyurtlu, I. \& Cabrita, I., The study of reactions influencing the biomass steam gasification process $\_$. Fuel, 82(7), pp. 835-842, 2003. https://doi. org/10.1016/s0016-2361(02)00313-7 
[3] Rowe, P. \& Nienow, A.W., Minimum fluidisation velocity of multi-component particle mixtures. Chemical Engineering Science, 30(11), pp. 1365-1369, 1975. https://doi. org/10.1016/0009-2509(75)85066-4

[4] Noda, K., Uchida, S., Makino, T. \& Kamo, H., Minimum fluidization velocity of binary mixture of particles with large size ratio. Powder Technology, 46(2-3), pp. 149-154. https://doi.org/10.1016/0032-5910(86)80021-3

[5] Jayarathna, C. \& Halvorsen, B., Experimental and computational study of particle minimum fluidization velocity and bed expansion in a bubbling fluidized bed. in SIMS. 2009.

[6] Huilin, L., Yunhua, Z., Ding, J., Gidaspow, D. \& Wei, L., Investigation of mixing/segregation of mixture particles in gas-solid fluidized beds. Chemical Engineering Science, 62(1-2), p. 301-317, 2007. https://doi.org/10.1016/j.ces.2006.08.031

[7] Oliveira, T., Cardoso, C. \& Ataíde, C., Bubbling fluidization of biomass and sand binary mixtures: Minimum fluidization velocity and particle segregation. Chemical Engineering and Processing: Process Intensification, 72, pp. 113-121, 2013. https://doi. org/10.1016/j.cep.2013.06.010

[8] Pérez, N.P., Pedroso, D.T., Machin, E.B., Antunes, J.S., Ramos, R.A.V. \& Silveira, J.L., Fluid dynamic study of mixtures of sugarcane bagasse and sand particles: Minimum fluidization velocity. Biomass and Bioenergy, 107, pp. 135-149, 2017. https://doi. org/10.1016/j.biombioe.2017.08.015

[9] Ramakers, B.J., De Ridder, R. \& Kerkhof, P.J., Fluidization behavior of wood/sand mixtures. Maderas. Ciencia y tecnologia, 6(2), pp. 145-153, 2004. https://doi.org/10.4067/ s0718-221x2004000200005

[10] Paudel, B. \& Feng, Z.G., Prediction of minimum fluidization velocity for binary mixtures of biomass and inert particles. Powder Technology, 237, pp. 134-140, 2013. https://doi.org/10.1016/j.powtec.2013.01.031

[11] Kunii, D. \& Levenspiel, O., High-Velocity Fluidization. Fluidization Engineering, 193-210, Elsevier, 2013. https://doi.org/10.1016/b978-0-08-050664-7.50014-7

[12] Kunii, D. \& Levenspiel, O., Circulating fluidized-bed reactors. Chemical Engineering Science, 52(15), pp. 2471-2482, 1997. https://doi.org/10.1016/s0009-2509(97)00066-3

[13] Cocco, R., Karri, S.R. \& Knowlton, T., Introduction to fluidization. Chem. Eng. Prog, 110(11), pp. 21-29, 2014.

[14] Niven, R.K., Physical insight into the Ergun and Wen \& Yu equations for fluid flow in packed and fluidised beds. Chemical Engineering Science, 57(3), pp. 527-534, 2002. https://doi.org/10.1016/s0009-2509(01)00371-2

[15] Wen, C. \& Yu, Y., A generalized method for predicting the minimum fluidization velocity. AIChE Journal, 12(3), pp. 610-612, 1966. https://doi.org/10.1002/aic.690120343

[16] Richardson, J. \& M.d.S. Jerónimo, Velocity-voidage relations for sedimentation and fluidisation. Chemical Engineering Science, 34(12), pp. 1419-1422, 1979. https://doi. org/10.1016/0009-2509(79)85167-2

[17] Doichev, K. \& Akhmakov, N., Fluidisation of polydisperse systems. Chemical Engineering Science, 34(11), pp. 1357-1359, 1979. https://doi.org/10.1016/00092509(79)80032-9

[18] Lin, C.L., Wey, M.Y. \& You, S.D., The effect of particle size distribution on minimum fluidization velocity at high temperature. Powder Technology, 126(3), pp. 297-301, 2002. https://doi.org/10.1016/s0032-5910(02)00074-8

[19] Ku, X., Li, T. \& Løvås, T., CFD-DEM simulation of biomass gasification with steam in a fluidized bed reactor. Chemical Engineering Science, 122, pp. 270-283, 2015. https:// doi.org/10.1016/j.ces.2014.08.045 